Review began 11/30/2021 Review ended 12/11/2021 Published 12/14/2021

(c) Copyright 2021

Thakral et al. This is an open access article distributed under the terms of the Creative Commons Attribution License CC-BY 4.0. which permits unrestricted use, distribution, and reproduction in any medium, provided the original author and source are credited.

\section{Multidrug-Resistant Stenotrophomonas maltophilia Keratitis in a Penetrating Keratoplasty Patient}

\author{
Nikhil Thakral ${ }^{1}$, Fraser S. Peck ${ }^{2,3}$, Pantelis Ioannidis ${ }^{3}$ \\ 1. Family Medicine, Trevelyan House Surgery, London, GBR 2. Pharmaceutical Medicine, Richmond Pharmacology, \\ London, GBR 3. Ophthalmology, Eastbourne District General Hospital, Eastbourne, GBR
}

Corresponding author: Nikhil Thakral, nikhilthakral93@gmail.com

\section{Abstract}

We describe the management of a case of multidrug-resistant Stenotrophomonas maltophilia in a patient who had previously undergone photorefractive keratectomy and subsequent penetrating keratoplasty for Schnyder's crystalline corneal dystrophy. This pathogen is rare and, in this case, was multi-drug resistant.

Categories: Ophthalmology, Infectious Disease

Keywords: multidrug-resistant, microbial keratitis, multidrug-resistant pathogen, keratoplasty, bacterial keratitis, maltophilia, stenotrophomonas

\section{Introduction}

This article was presented as an e-poster at the 2021 Scottish Clinical Fellow Conference on November 10, 2021.

Bacterial keratitis is a significant corneal pathology linked to corneal scarring and is associated with up to $5 \%$ of global blindness [1]. Factors that can increase the risk of infectious keratitis include contact lens wear, ocular surface diseases, corneal surgery and trauma [2].

An example of such an ocular surface disease is Schnyder's crystalline corneal dystrophy. This is an autosomal dominant disease characterised by bilateral progressive corneal opacification leading to reduced visual acuity and glare. Penetrating keratoplasty is the management of choice to recover vision quality [3].

Accurate, early diagnosis of the causative organism in bacterial keratitis is key as it allows for targeted antimicrobial therapy based on sensitivities [4]. Strenotrophomonas maltophilia is a gram-negative bacillus that has also been implicated as a hospital-acquired respiratory pathogen [5]. S. maltophilia has previously been implicated in bacterial keratitis [6].

\section{Case Presentation}

A 77-year-old female patient presented to ophthalmic services with a 10-day history of blurred vision in her left eye. There is a past medical history of Schnyder's crystalline corneal dystrophy. This was treated with photorefractive keratectomy 10 years previously in the affected eye and then a penetrating keratoplasty two years previously in the affected eye. The patient also has primary open-angle glaucoma. There was no concurrent contact lens usage. Treatment at presentation included loteprednol etabonate $0.5 \%$, latanoprost $0.005 \%$ and timolol $0.5 \%$ eye drops.

On examination, her pinhole visual acuity in the left eye was 6/24 and rebound tonometry of $9 \mathrm{~mm} \mathrm{Hg}$. There was a 2 by $2 \mathrm{~mm}$ epithelial defect with epithelial oedema, mild stromal haze and hyperaemia (Figures $1 \mathrm{~A}$, $1 B)$, there was no anterior chamber reaction. 


\section{Cureus}

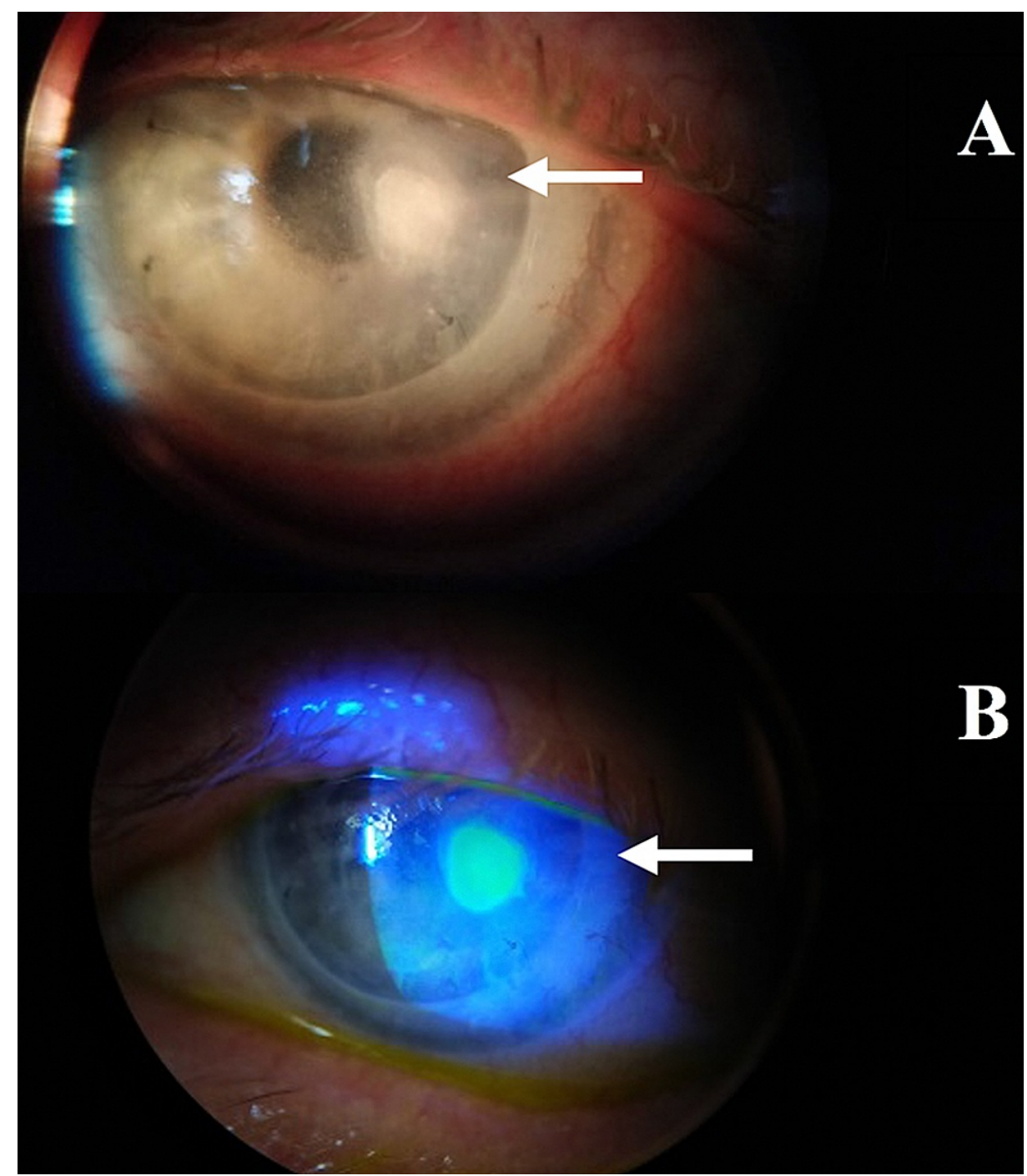

FIGURE 1: (A) Slit-lamp biomicroscopy of the S. maltophilia ulcer in the left eye (see top arrow). (B) Fluorescein staining shows the epithelial defect of the ulcer (see bottom arrow).

A corneal scrape was conducted, a culture was taken and used for MALDI-TOF analysis. The organism was identified as S. maltophilia (Table 1) showing multidrug resistance. Initial management with an intensive course of preservative-free cefuroxime $5 \%$ and gentamicin $1.5 \%$ reducing with time, also loteprednol etabonate $0.5 \%$ was stopped. 


\section{Cureus}

\begin{tabular}{|l|l|}
\hline Antibiotic & Sensitivity \\
\hline Amikacin & Resistant \\
Amoxicillin & Resistant \\
Aztreonam & Resistant \\
Cefotaxime & Resistant \\
Cefuroxime & Resistant \\
Chloramphenicol & Resistant \\
\hline Ciprofloxacin & Resistant \\
Co-Amoxiclav & Resistant \\
Co-Trimoxazole & SENSITIVE \\
Cefpodoxime & Resistant \\
\hline Ertapenem & Resistant \\
Gentamicin & Resistant \\
\hline Piperacillin-tazobactam & Resistant \\
Trimethoprim & Resistant \\
\hline
\end{tabular}

TABLE 1: The antibiotic sensitivities of the corneal scrape isolate

Following sensitivities, oral Co-Trimoxazole, 960mg, twice a day was initiated and given for three weeks. Cefuroxime $5 \%$ drops were changed to preservative-free levofloxacin $0.5 \%$ on a reducing course. One week later, the epithelium defect had lessened to 1 by $2 \mathrm{~mm}$, with mild anterior chamber activity and keratic precipitates. At this point, hydrocortisone $0.335 \%$, two drops, four times a day was initiated.

Following an eight-week treatment regimen, a small stable corneal scar remains. The corneal graft is clear with no signs of rejection and pinhole visual acuity of 6/18 is observed in the left eye. Lubricating eye drops have been initiated with dexamethasone $0.1 \%$ once daily to encourage scar remodulation.

\section{Discussion}

A key element in ocular infections caused by S. maltophilia is ocular surface instability [7]. Corneal epithelial cells secrete surfactant proteins which can inhibit microbial infection. In cases where the barrier of corneal epithelial cells is compromised, there is a reduction in the intrinsic antimicrobial properties of the tear film. This can facilitate the growth of opportunistic infections such as S. maltophilia [8]. In this case, the previous history of Schnyder's crystalline corneal dystrophy, photorefractive keratectomy, penetrating keratoplasty and the use of loteprednol etabonate were likely risk factors by altering the natural resistance to infection [2].

This case highlights a relatively uncommon pathogen affecting the eye. Its most frequent manifestations are pneumonia and bacteremia [5]. There is reported literature that implicates this organism as a cause of bacterial keratitis [8]. In one case series, S. maltophilia was isolated from polybacterial ocular infections in 10 out of 15 cases suggesting this pathogen may be more common than previously thought [6]. This case also highlights the use of oral Co-Trimoxazole as there was no commercial ophthalmic preparation available.

S. maltophilia has intrinsic microbial resistance. This includes an impermeable outer membrane which makes it resistant to most antibiotics [9] as well as the production of two beta-lactamases (L1 and L2), conferring resistance to beta-lactam-containing antibiotics [10]. Multidrug-resistant bacteria are a growing global concern and are considered a major public health problem [11].

A recent case series recommended high bacterial sensitivity to fluoroquinolones (93\%), gentamicin (88\%) and beta-lactam (81\%) classes of antibiotics. It also suggests that concurrent use of fluoroquinolone, betalactam and an aminoglycoside should be considered first-line treatment [8]. In this case, the isolated strain of S.maltophilia showed multidrug resistance to commonly prescribed topical antibiotics and was only sensitive to Co-Trimoxazole. 


\section{Conclusions}

S. maltophilia as a cause of bacterial keratitis is uncommon. It is also apparent that concerns regarding the management of multi-drug resistant pathogens are growing and it is a significant public health problem. In cases where there is no commercial ophthalmic preparation for an antibiotic, oral antibiotics can be used. Prompt and accurate diagnosis of the causative organism helps to reduce the risk of prolonged infection, reducing permanent damage to vital ocular tissues and subsequent morbidity.

\section{Additional Information}

\section{Disclosures}

Human subjects: Consent was obtained or waived by all participants in this study. Conflicts of interest: In compliance with the ICMJE uniform disclosure form, all authors declare the following: Payment/services info: All authors have declared that no financial support was received from any organization for the submitted work. Financial relationships: All authors have declared that they have no financial relationships at present or within the previous three years with any organizations that might have an interest in the submitted work. Other relationships: All authors have declared that there are no other relationships or activities that could appear to have influenced the submitted work.

\section{References}

1. Ung L, Bispo PJ, Shanbhag SS, Gilmore MS, Chodosh J: The persistent dilemma of microbial keratitis: global burden, diagnosis, and antimicrobial resistance. Surv Ophthalmol. 2019, 64:255-71. 10.1016/j.survophthal.2018.12.003

2. Khor WB, Prajna VN, Garg P, et al.: The Asia Cornea Society Infectious Keratitis Study: a prospective multicenter study of infectious keratitis in Asia. Am J Ophthalmol. 2018, 195:161-70. 10.1016/j.ajo.2018.07.040

3. Sarosiak A, Udziela M, Ścieżyńska A, Oziębło D, Wawrzynowska A, Szaflik JP, Ołdak M: Clinical diversity in patients with Schnyder corneal dystrophy-a novel and known UBIAD1 pathogenic variants. Graefes Arch Clin Exp Ophthalmol. 2018, 256:2127-34. 10.1007/s00417-018-4075-9

4. Austin A, Lietman T, Rose-Nussbaumer J: Update on the Management of Infectious Keratitis . Ophthalmology. 2017, 124:1678-89. 10.1016/j.ophtha.2017.05.012

5. Looney WJ: Role of Stenotrophomonas maltophilia in hospital-acquired infection . Br J Biomed Sci. 2005, 62:145-54; quiz $1 \mathrm{p}$ following 154. 10.1080/09674845.2005.11732702

6. Chen YF, Chung PC, Hsiao CH: Stenotrophomonas maltophilia keratitis and scleritis. Chang Gung Med J. 2005, 28:142-50.

7. Penland RL, Wilhelmus KR: Stenotrophomonas maltophilia ocular infections . Arch Ophthalmol. 1996, 114:433-6. 10.1001/archopht.1996.01100130429013

8. Park BC, Lim HR, Park SJ, Koh JW: Clinical features and management of Stenotrophomonas maltophilia keratitis. Ophthalmol Ther. 2021, 10:525-33. 10.1007/s40123-021-00348-z

9. Yang Z, Liu W, Cui Q, et al.: Prevalence and detection of Stenotrophomonas maltophilia carrying metallo- $\beta$ lactamase blaL1 in Beijing, China. Front Microbiol. 2014, 5:692. 10.3389/fmicb.2014.00692

10. Alonso A, Martínez JL: Multiple antibiotic resistance in Stenotrophomonas maltophilia . Antimicrob Agents Chemother. 1997, 41:1140-2. 10.1128/AAC.41.5.1140

11. Roca I, Akova M, Baquero F, et al.: The global threat of antimicrobial resistance: science for intervention . New Microbes New Infect. 2015, 6:22-9. 10.1016/j.nmni.2015.02.007 